\title{
Систематизация накшабандии:
} Мухаммад Парса (ум. 1420) и его «Рисала-йи Кудсийа»

\author{
С.С. Гайнуллин ${ }^{1 a}$ \\ ${ }^{1}$ Болгарская исламская академия, г. Болгар, Российская Федерация \\ ${ }^{a}$ ORCID: https://orcid.org/0000-0001-8149-9867, e-mail: manara.tatar@mail.ru
}

Резюме: В настоящей статье предпринята попытка анализа трактата Мухаммада Парсы (ум. 1420) «Рисала-йи Кудсийа», являющегося одной из важнейших работ накшабандийского тариката, который оказал существенное влияние на духовную культуру татар и многих других мусульманских народов России. Эта книга являлась первой систематизацией истории, основных принципов и практик этого ордена. В ней приводится неразрывная цепочка (силсила) его духовных наставников, которой обосновывается богословско-правовая легитимность его учения, как непосредственно связанная с Сунной пророка Мухаммада и его сподвижников. В работе особое внимание уделяется необходимости искренней любви и безукоризненного подчинения своему наставнику как хранителю не только явного, но и сокровенного знания, переданного от Пророка. В статье приводится также краткая биография М. Парсы и список его основных работ.

Ключевые слова: Мухаммад Парса; «Рисала-йи Кудсийа» («Послание о святости»); накшабандийский тарикат; суфизм (тасаввуф)

Для цитирования: Гайнуллин С.С. Систематизация накшабандии: Мухаммад Парса (ум. 1420) и его «Рисала-йи Кудсийа». Minbar. Islamic Studies. 2021;14(2):397-410 DOI: 10.31162/2618-9569-2021-14-2-397-410

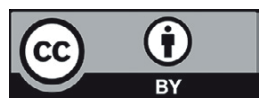

Контент доступен под лицензией Creative Commons Attribution 4.0 License.

This work is licensed under a Creative Commons Attribution 4.0 License. 


\title{
Naqshabandi systematization: Muhammad Parsa (d. 1420) and his «Risala yi Qudsiyya»
}

\author{
S.S. Gainullin ${ }^{1 a}$ \\ ${ }^{1}$ Bolgar Islamic Academy, Bolgar, the Russian Federation \\ ${ }^{a}$ ORCID: https://orcid.org/0000-0001-8149-9867,e-mail:manara.tatar@mail.ru
}

\begin{abstract}
This article attempts to analyze the treatise of Muhammad Parsa (d. 1420) "Risala yi Qudsiyya”, which is one of the most important works of the Naqshabandi tariqah, which had a significant impact on the spiritual culture of Tatars and on many other Muslim peoples of Russia. This book was the first systematization of the history, of the basic principles and practices under this order. It provides an unbreakable chain (silsila) of his spiritual mentors, which substantiates the theological and legal legitimacy of his teachings, as directly related to the Sunnah of Prophet Muhammad and his companions. The work also pays special attention to the need for sincere love and impeccable obedience to your mentor as to the custodian of not only explicit, but also of sacred knowledge transmitted from the Prophet. The article also provides M. Parsa's short biography and a list of his main works.
\end{abstract}

Keywords: Muhammad Parsa; "Risala-yi Qudsiyya” (“Message of Holiness”); Naqshabandi Tariqah; Sufism (Tasawwuf)

For citation: Gainullin S.S. Naqshabandi systematization: Muhammad Parsa (d. 1420) and his "Risala yi Qudsiyya". Minbar. Islamic Studies. 2020;14(2):397-410 (In Russ.) DOI: $10.31162 / 2618-9569-2021-14-2-397-410$

\section{Введение}

Накшабандийа - одно из самых распространенных сегодня суннитских суфийских братств. Свое духовное учение оно возводит к пророку Мухаммаду через двух его ближайших сподвижников - Абу Бакра и 'Али, а непосредственным основателем считает Йусуфа ал-Хамадани (ум. 1140). Ученик последнего - ал-Гидждувани (ум. ок. 1200) стал основателем ордена хваджаган. Его теоретические и практические положения в конце XIV в. были дополнены крупнейшим среднеазиатским мистиком того периода Бахауддином Накшабандом (1318-1389). В то же время сам эпоним этой мистической школы не оставил после себя письменных трудов, и его учение было систематизировано и сохранено для потомков стараниями учеников - Аляутдином Аттаром (ум. в 1400) и особенно Мухаммадом Парсой (ум. 1420). Они же сыграли 
Гайнуллин С.С.

Систематизация накшабандии:

Мухаммад Парса (ум. 1420) и его «Рисала-йи Кудсийа»

основную роль в консолидации братства и расширении его влияния. Накшабандийа получило широкое распространение по всему мусульманскому миру, в различных регионах которого выделились его местные ответвления, ставшие самостоятельными братствами [1, с. 185].

B XVII-XVIII вв. учение этого тариката стало проникать из Средней Азии в Волго-Уральский регион. Получая образование в религиозных центрах Бухары и Самарканда, многие татарские студенты приобщались здесь к накшабандии и затем, возвращаясь на родину, распространяли его идеи среди соплеменников. Во второй половине XVIII - первой половине XIX вв. идеи и институты этого братства оказывали существенное влияние не только на развитие богословской и общественной мысли, но и на многие другие стороны жизни татарского общества - от семейно-бытовых до общественно-политических [2, с. 15-16].

В этой связи изучение истории и анализ богословских идей данного суфийского ордена, оказавшего существенное влияние на духовную культуру татар и многих других мусульманских народов нашей страны, представляется весьма актуальным.

Объектом настоящего исследования является систематизация накшабандийского тариката, выполненная Мухаммадом Парсой, предметом - его труд «Рисала-йи Кудусийа», в котором разъясняются основные положения этого ордена и собственный взгляд на его духовную историю.

\section{Несостоявшийся преемник Накшабанда: штрихи к биографии}

Предание гласит, что однажды в дом Накшабанда постучал мальчик по имени Мухаммад. Увидев его, слуга сказал хозяину, что пришел молодой человек, «похожий на аскета (перс. - парса)». Выйдя навстречу гостю, шейх сказал, что отныне именно так («Парса») и будет величать своего нового ученика [3, с. 7-8]. В будущем ему суждено было не только продолжить аскетический путь учителя, но и стать главным систематизатором его учения.

Мухаммад Парса родился в 749 г.х./1348 г. в Бухаре в семье потомственных богословов ханафитской школы. Некоторые биографы возводят его родословную к общепризнанному как шиитами, так и суннитами имаму Джа- 
фару ас-Садику (702-765), который, являясь потомком Пророка, также считается одним из передатчиков от него особого суфийского знания. В то же время достоверно известно, что одним из предков Парсы был крупнейший законовед того времени Хафиз ад-Дин ал-Кабир ал-Бухари (ум. 1291 или 1294).

Он получил достойное воспитание и уже с раннего возраста проявил интерес к богословским наукам и стремление к постижению тасаввуфа. Став одним из ближайших учеников Накшабанда, он дважды совершил вместе с ним паломничество ( $х а д ж)$. Учитель всегда очень лестно отзывался о Парсе, дал ему разрешение на духовное наставничество (иджаза) и считал его одним из своих преемников [4, с. 391-392]. Однако после смерти Накшбанда в 1389 г. Парса не стал главой ордена, уступив место своему «однокласснику» Аляутдину Аттару (ум. 1400) и приняв его духовное наставничество.

Будучи большим специалистом, помимо суфизма, еще и в области мусульманского права и хадисоведения, шейх Мухаммад Парса посвятил свою жизнь преподавательской и научной деятельности. В своих трудах он опирался в первую очередь на традиции домонгольской школы Мавераннахра, особенно Хорасана. Им была собрана уникальная библиотека старинных и редких рукописей, которая продолжала функционировать в его обители ( $x a$ нака) вплоть до второй половины ХІХ в. [5].

Богослов умер в 1420 г. в Медине и был похоронен на знаменитом кладбище сподвижников Пророка «Джаннат ал-баки» рядом с могилой его дяди Аббаса (566-653) [3, с. 10].

\section{Богословское наследие Мухаммада Парсы}

Перу шейха Мухаммада Парсы принадлежит множество произведений по различным дисциплинам мусульманского богословия. Перечислим наиболее известные:

1. «Фасл ал-хитаб» («Окончательное решение»). Этот труд написан на персидском языке. В большей степени он посвящен разъяснению ряда понятий тасаввуфа, основ накшбандийского тариката и описанию нравственных качеств, которые должны воспитать в себе его последователи. В нем также 
Гайнуллин С.С.

Систематизация накшабандии:

Мухаммад Парса (ум. 1420) и его «Рисала-йи Кудсийа»

повествуется о сподвижниках пророка Мухаммада, потомках из его рода и некоторых великих духовных подвижниках ислама. Эта книга была переведена на турецкий и арабский языки. Турецкое издание известно под названием «Тевхиде гериш» («Введение в единобожие») [6].

2. «Тухфат ас-саликин» («Шедевр ходящих»). Работа содержит в себе избранные главы предыдущей книги. В 1970 г. она была издана в Дели.

3. «Макамат шайх 'Ала ад-дин 'Аттара» («Духовное совершенство шейха Аляутдина Аттара»). Труд представляет собой сборник высказываний Аляутдина Аттара. Фрагменты этой книги в последующем были включены Али Сафи ал-Кашифи ${ }^{1}$ в его сборник жизнеописаний суфийских шейхов под названием «Рашахат 'айн ал-хайят» («Капли из источника вечной жизни»).

4. «Тафсир сувари самания» («Комментарий восьми сур») - это комментарий на персидском языке к 97-104 сурам Корана. Книга была написана в 1417 г. В библиотеке «Сулеймание» в Стамбуле имеются две ее рукописных копии 2 .

5. «Тафсир сурат ал-Фатиха» (Комментарий суры «Открывающая») комментарий к 1-й суре Корана на персидском языке. Ее единственная рукопись хранится в государственной библиотеке Стамбула.

6. «Рисала-ий кашфийа» («Раскрывающая трактат»). В труде рассматриваются традиционные суфийские темы - зикр (поминание Аллаха), махабба (любовь к Аллаху) и вахдат ал-вуджуд (единство бытия). Этот труд был переведён с персидского на турецкий язык [7].

7. «Рисала-ий дар ал-байан зикр ал-джахри» («Трактат, разъясняющий поминание вслух»). Работа представляет собой ответ Мухаммада Парсы на вопрос учёного из города Герата о допустимости громкого зикра. Автор доказывает дозволенность этого через сопоставление этого действия с чтением вслух Корана, являющегося дозволенным.

8. «Фусуль ас-ситта» («Шесть разделов»). Труд, написанный на арабском языке, посвящён методологии выведения правовых норм (ахкам) из ха-

\footnotetext{
1 Али Сафи, Фахр ад-дин Али ибн Камаль ад-дин Хусейн Ваиз Кашифи (1463?- между 1531 и $1533)$ - персидский мусульманский учёный, поэт, писатель, влиятельный проповедник и моралист, известный также как Мавляна Ваиз Кашифи или просто мулла Хусейн.

2 Библиотека Сулеймания, г. Стамбул. Багдатлы вахби Ефанди. Оп. 63; Шехид Али Паша, № 113.
} 
дисов. Одна рукописная копия этого труда хранится в библиотеке им. Лобачевского в г. Казани ${ }^{3}$.

9. «Шарх хакк ал-йакин» («Комментарии к верной истине»). Работа является комментарием к книге Махмуда Шабистари ${ }^{4}$. Ее рукопись хранится в библиотеке «Рашид Эфенди» в г. Кайсери в Турции.

10. «Анису ат-талибин ва уддат ас-саликин» («Собеседник ищущих и приспособление идущих»). Эта книга на персидском языке повествует о достоинствах ищущих знание.

11. «Рисала ал-мазарат» («Трактат о посещении священных мест»). В этом труде, написанном на персидском языке, повествуется об исторических достопримечательностях Иерусалима, Багдада и городов Леванта.

12. «Рисала махбубийа». («Трактат о любимых»). Труд написан на персидском языке. Он посвящен разъяснению суфийского понимания любви к Аллаху, нравственности, аскетизма и богобоязненности.

13. «Рисалат мунтахаб мин 'акида Аби ал-Касим ас-Самарканди». («Сборник сочинений о вероубеждении Абу ал-Касыма ас-Самарканди «). Описание матуридитского вероучения. Рукопись хранится в библиотеке «Сулеймание» в Стамбуле.

14. «Тафа“улат» («Взаимодействия»). Это комментарии к избранным айатам Корана на персидском языке.

15. «Шарх фусуль ал-хикам» («Разъяснение глав мудрости»). Это комментарии к труду «Фусул ал-хикам» Мухиддина ибн ал-'Араби ${ }^{6}$ на персидском языке.

${ }^{3}$ Отдел рукописей и редких книг Казанского Федерального Университета им. Н.И. Лобачевского (ОР РК КФУ) Фонд 10. Оп. 695. Л. 31. об. 166.

${ }^{4}$ Махмуд Шабистари родился в городе Шабестар близ Тебриза в 1288 году (687 г.х.), где и получил начальное образование. Одним из важнейших учителей Шабистари был суфийский шейх Амин ад-дин Тебризи, а его духовным учителем и наставником - Бахауддин Якуб Тебризи. Шабистари в основном сосредоточился на суфизме, теологии и философии. Свои произведения он писал в период, когда страна оказалась под властью монголов.

5 Абу ал-Касим ал-Хаким ас-Самарканди (ум. 342/953), был ханафитским богословом, кади (судьей) некоторые источники называют его учеником имама ал-Матуриди.

${ }^{6}$ Ибн ал-'Араби, Абу Бакр Мухаммад ибн Али Мухиддин (1165, Мурсия, Андалусия, ныне Испания 1240 , Дамаск) - арабо-мусульманский философ, мистик и поэт; известен как «Величайший шейх» суфизма. Среди огромного наследия (более 800 сочинений) выделяются «Мекканские откровения» духовный дневник последних трёх десятилетий его жизни, своеобразная эзотерическая «Энциклопедия суфизма». Особенно популярная среди суфиев книга «Геммы мудрости» была переведена на многие языки мира, к ней было составлено свыше 150 комментариев [8, с. 246-247]. 
Гайнуллин С.С.

Систематизация накшабандии:

Мухаммад Парса (ум. 1420) и его «Рисала-йи Кудсийа»

16. «Рисала-йи Кудсийа» (Послание о святости).

\section{«Рисала-йи Кудсийа»}

Важнейшим трудом Мухаммада Парсы стала книга «Рисала-йи Кудсийа», в которой систематизированы основные понятия накшабандийского тариката, а также его духовная история.

Она по сути представляет собой учебное пособие для последователей этого братства, использует его термины и символический язык, не всегда понятный неподготовленному читателю. Ее основной темой являются практические вопросы мистического пути. Вместе с этим в книге также кратко затрагиваются некоторые теоретические положения интеллектуального мистицизма и история развития тариката. Многие положения изложены тезисно, без логических связок тем между собой.

Работа является скорее компилятивным, чем оригинальным произведением, содержит многочисленные вкрапления из трудов более ранних авторов, не выделенные как цитаты. Примерно одна треть книги, которую условно можно назвать вводной частью, представляет собой переложение вступления к сочинению «Тазкират ал-аулийа» Аляутдина Аттара (ум. 1400) $[9$, c. 274$]$.

«Рисала-йи Кудсийа» была переведена на османский [10] и русский [9] языки. Оба этих перевода были использованы при анализе текста в настоящем исследовании. Для разъяснения суфийских символических выражений и терминов мы также обращались к османскому комментарию этой книги Абдаллы Салахи, являющегося последователем накшабандийского тариката по той же цепочке духовной преемственности, что и Парса [10]. Помимо этого, в процессе изучения работы мы обращались и к другим накшабандийским трактатам - рукописи Мухаммада Мурада «Силсилят аз-Захаб» ${ }^{7}$ [11], ее переводу, выполненному Мухаммадом Рустемом Рашидом [10], и заметкам ‘Абд ал-Хакима ал-Арваси ${ }^{8}[12]$.

\footnotetext{
7 Мурад М. Силсилат аз-захаб фи ас-сулук ва ал-адаб. Стамбул: Библиотека Сулеймании. Отдел рукописи. Ф. 1203. 1752. С. 1-18. [Электронный ресурс]. - Режим доступа: https://ru.scribd.com/ doc/76647756/Silsilah-az-Zahab-Fi-as-Sulook-wa-al-Adab-Arabic-manuscript (дата обращения: 10.11.2020)

8 'Абд ал-Хаким ал-Арваси (1865-1943) - 33-й шейх накашабандийского тариката, муджтахид.
} 


\section{Структура книги «Рисала-йи Кудсийа»}

Нами было выделено 12 тематических частей:

Часть 1 [9, с. 275-299].

В этой части повествуется об основах вероубеждения (акида), необходимости религиозной практики, опасности внесения в нее любого рода новшеств, необходимости сторониться различных послаблений (pyхса) в религии и стремлении следовать ей с большей строгостью ('азима). В ней также говорится об основных принципах накшабандийского тариката всегда и во всех случаях и обстоятельствах сохранять связь с Всевышним Аллахом, во время совершения всех видов поклонений душой и телом следовать исключительно Сунне, а также быть в тесной связи с духовным наставником, испытывая к нему искреннюю привязанность, почтение и уважение. Далее сообщается, что каждый человек, руководствуясь вышеприведёнными предписаниями, по воле Всевышнего Аллаха сможет достичь высоких духовных степеней.

Здесь же разъясняется, что накшабандийский тарикат называют «золотой цепью» (силсилат аз-захаб) в связи с тем, что братство возводит свое учение по цепочке духовных наставников к пророку Мухаммаду как духовно - через его первого халифа Абу Бакра, так и по родословной - через его зятя 'Али [1, с. 186-187].

Далее Парса приводит саму эту цепочку:

Пророк Мухаммад (570-632) $\rightarrow$ Абу Бакр ас-Сиддик (572-634) $\rightarrow$ Салман ал-Фариси (578-657) $\rightarrow$ Касим ибн Мухаммад (653-725) $\rightarrow$ Джафар ас-Садик (702-765) $\rightarrow$ Баязид Бистами (804-874) $\rightarrow$ Абу ал-Хасан Харкани (962-1034) $\rightarrow$ Абу Али Фармади (1016-1084) $\rightarrow$ Юсуф Хамадани (1048$1140) \rightarrow$ 'Абд ал-Халик Гиждувани (1103-1179) $\rightarrow$ Арифи Рифгари (ум. 1183) $\rightarrow$ Махмуд Анжир Фагнавий (ум. 1317) $\rightarrow$ Али Рамитани (1195-1321) $\rightarrow$ Мухаммад Баба Саммаси (ум. 1389) $\rightarrow$ Сейид Амир Кулаль (ум 1370) $\rightarrow$ Бахауддин Накшбанд (1318-1389) [10, с. 13-18].

Часть 2 [9, с. 300-304].

В начале второй части раскрываются значения двух атрибутов Аллаха - ат-Таййиб «Прекрасный» и ал-'Азим «Великий», причем Парса особо 


\section{Гайнуллин С.С.}

отмечает, что эти качества в некоторой степени проявляются и в духовных лидерах, и в последователях накшабандийского тариката.

Далее говорится о том, что в сердцах верующих страх (хауф) перед Богом должен преобладать над надеждой ( $р а д ж а)$ на Его прощение.

В конце этой части сообщается о том, что только путь духовного самосовершенствования придает жизни подлинный смысл, тогда как его отсутствие подобно смерти.

Часть 3 [9, с. 304-312].

В этой части книги рассматриваются специальные вопросы тасаввуфа: близость к Богу (курбу ли-Ллах) и отдаленность от Него (бу'd 'ани-Ллах), движение к Богу (сайир ли-Ллах) и движение с Ним (сайир фи-Ллах). Здесь также говорится о необходимости признания и полного подчинения духовному наставнику (муршиду), ибо любить и следовать за ним - значит «любить и следовать за посланником Аллаха и Самим Аллахом». Далее приводится свод этических предписаний, которые должен соблюдать последователь тариката (мурид) по отношению к своему духовному наставнику.

Часть 4 [9, с. 312-316].

Здесь повествуется о проявлении ряда Божьих эпитетов на различных этапах пути духовного самосовершенствования мурида.

Часть 5 [9, с. 316-320].

В этой части раскрывается важность зикра (поминания Аллаха), описывается практика зикра, осознание зависимости от Бога и размышлений о смерти. В частности, указывается на достоинство чтения Корана, на формы громкого и тихого зикра.

Часть 6 [9, с. 320-343].

Она посвящена раскрытию двух духовных степеней - талвин «окрашивание» и тамкин «взвешенность». Достигший тамкина является тем, кто получил сверхъестественные знания ('илм ладунний), продолжая при этом, как и все другие люди, удовлетворять свои естественные физиологические потребности. 
Часть 7 [9, с. 343-345].

Здесь говорится о том, что приближённые к Аллаху люди имеют разные духовные степени. Они отличаются друг от друга разным уровнем знаний и способом познания, проницательностью, а также тем, что одни могут руководствоваться послаблениями (рухса) в религии, а другие будут исполнять все в строгости.

Часть 8 [9, с. 345-351].

Эта часть посвящена таким важным принципам накшабандийского тариката, как разумное ограничение себя в еде, питье, сне, а также признание собственной слабости и несовершенства.

Часть 9 [9, с. 351-354].

Она повествует о таких суфийских понятиях, как халва «уединение», 'узла «отрешённость» и нийа «намерение».

Часть 10 [9, с. 354-355].

Здесь повествуется о необходимости полного смирения перед Божьей волей и Его предопределением.

Часть 11 [9, с. 356-359].

Подробно рассматриваются такие понятия суфизма, как сулук «духовный путь саморазвития», джазбб «любовь к Аллаху», а также разъясняется, что есть путь Пророка и путь приближенных к Аллаху. Здесь ещё раз подчёркивается, что накшабандийский тарикат получил своё начало от самих сподвижников посланника Аллаха. А это значит, что ему свойственно строгое следование Сунне и отказ от послаблений в религии (рухса). Кроме этого, еще раз повторяется необходимость следовать духовному наставнику, испытывая к нему искреннюю любовь и почтение как к наследнику Пророка.

Часть 12 [9, с. 360-372].

В этой части книги раскрываются такие понятия суфизма, как фана «саморастворение» и бака «растворение». 


\section{Гайнуллин С.C.}

Систематизация накшабандии:

Мухаммад Парса (ум. 1420) и его «Рисала-йи Кудсийа»

\section{Заключение}

Трактат «Рисала-йи Кудсийа» стал первой систематизацией истории, основных принципов и практик накшабандийского тариката. Здесь приводится неразрывная цепочка (силсила) его духовных наставников, восходящая к самому пророку Мухаммаду и заканчивающаяся учителем автора - эпонимом этого братства - Бахауддином Накшабандом. Этим обосновывается и богословско-правовая легитимность его учения как непосредственно связанная с Сунной посланника Аллаха и его сподвижников. По этой причине особое внимание в работе уделяется необходимости искренней любви и безукоризненного подчинения своему наставнику как хранителю не только явного, но и сокровенного знания, переданного от Пророка. Как известно, до сих пор институт наставничества является основополагающим для суфизма.

Описанные Парсой понятия и методы духовного самосовершенствования получили свое развитие у последующих мистиков, однако именно его формулировки, данные в «Рисала-йи Кудсийа», лежат в основе всего учения накшабандии. Продолжение его изучения и подготовка в дальнейшем комментированного богословского перевода на русский язык этого средневеково трактата имеет очень важное значение как с литературоведческой, так и с богословской точки зрения.

\section{Литература}

1. Ислам: энииклопедический словарь. Прозоров С.М. (ред.) М.: Наука, ГРВЛ; 1991. 315 с.

2. Сабиров Н.Р. Роль суфийских традиций в развитии татарской общественной мысли XVII-XVIII вв.: дисс. ... канд. истор. наук. Казань, 2013. 165 с.

3. Тосун Н. Мухаммед Бахаеддин хазретлеринен сохбетлери. Стамбул: Эркам йайынларе; 1998. 55 с.

4. Ал-Курди М. ад-Далаил ал-А 'алия, ас-ила ва адджвиба фи ат-тасаввуф ва тарикат ас-садат ан-накшбандия. Каир: Дар ас-Са’ада; 2008. 386 с. 
5. Алгар Х. Мухаммед Парса. [Электронный ресурс]. - Режим доступа: https://islamansiklopedisi.org.tr/muhammed-parsa (дата обращения: 05.01.2020).

6. Хусревоглу А. Тевхиде Гирии, Мухаммад Парса. Стамбул: Китаб такипчилери; 2017. 528 с.

7. Парса М. Рисала-ий кашфийа. Карачан М. (пер.). Стамбул: Литера Йайынчылик; 2020. 120 с.

8. Али-заде А.А. Накшбандиты. Исламский эничиклопедический словарь. М.: Ансар; 2007. 609 с.

9. Парса М. Рисала-йи кудсийа. Трактат о святости. Мудрость суфиев. Ястребова О.М., Иоаннесян Ю.А., Бабаджанов Б.М. (пер. с персид.). СПб.: Азбука, Петербургское Востоковедение; 2001. С. 273-372.

10. Саляхи А. Рисаля-и кудсийа тарджумаси. Стамбул: Матба'а Ахмед Ахсен; 1323. 95 с.

11. Шимсек Х. Мурад Бухари. Т. 31. С. 185-187. [Электронный ресурс]. Режим доступа: https://islamansiklopedisi.org.tr/murad-buhari (дата обращения: 30.10.2020).

12. Арваси А. Саваних ал-афкар ва Савамих ал-анзар. Стамбул: Аситане; 2004. 233 c.

\section{References}

1. Islam: entsiklopedicheskiy slovar' [Islam: An Encyclopedic Dictionary]. Prozorov S.M. (ed.) Moscow: Nauka, Glavnaya redaktsiya vostochnoy literatury; 1991. 315 p. (In Russian)

2. Sabirov N.R. Rol'sufiyskikh traditsiy v razvitii tatarskoyobshchestvennoy mysli XVII-XVIII vv.: diss. ... kand. istor nauk [Role of Sufi Traditions in the Development of Tatar Social Thought of the 17th-18th Centuries: Dissertation in History thesis]. Kazan, 2013. 165 p. (In Russian)

3. Tosun N. Mukhammed Bakhaeddin khazretlerinen sokhbetleri [Muhammad Bahaeddin's conversations]. Istanbul: Erkam Yayınları; 1998. 55 p. (In Turkish) 
Гайнуллин С.C.

Систематизация накшабандии:

Мухаммад Парса (ум. 1420) и его «Рисала-йи Кудсийа»

4. Al-Kurdi M. ad-Dalail al-A'alia, asila va adjwiba at-tasavvuf va tarikat assadat an-naqshbandia [High directories questions and answers in Sufism and the way of the Naqshbandi masters]. Cairo: Dar as-Sa'ada; 2008. 386 p. (In Arabic)

5. Algar H. Muhammed Parsa. [Electronic source]. Available at: https:// islamansiklopedisi.org.tr/muhammed-parsa (Accessed: 05.01.2020). (In Turkish)

6. Husrevoglu A. Tevhide Girish, Muhammad Parsa [Introduction to faith, Muhammad Parsa]. Istanbul: Kitap Takipchileri; 2017. 528 p. (In Turkish)

7. Parsa M. Risale-i Keşfiyye [Message disclosure]. Karacan M. (tr.). Istambul: Litera Yayıncılık; 2020. 120 p. (In Turkish)

8. Ali-zade A.A. Nakshbandity [Naqshbandis]. Islamskiy ensiklopedicheskiy slovar' [Islamic Encyclopedic Dictionary]. Moscow: Ansar; 2007. 609 p. (In Russian)

9. Parsa M. Risala-yi kudsiya. Traktat o svyatosti [A treatise on Holiness]. Mudrost' sufiev [The wisdom of the Sufis.]. Yastrebov O.M., Ioannesyan Yu.A., Babadzhanov B.M. (tr.). St. Petersburg: Azbuka, Petersburg Vo-Stock Studies; 2001, pp. 273-372. (In Russian)

10. Salahi A. Risale-i Kudsiyye Tercumesi [Translation of Risala-yi Qudsiyya]. Istanbul: Matba’a Ahmad Ahsan; 1323. 95 c. (In Turkish)

11. Shimsek H. Murad al-Buhari. Vol. 31, pp. 185-187. [Electronic source]. Available at: https://islamansiklopedisi.org.tr/murad (Accessed: 30.10.2020). (In Turkish)

12. Arvasi A. Savanih al-afkar va Savamih al-anzar [Forgive the alarm and the thoughts]. Istanbul: Asitane; 2004. 233 p. (In Arabic)

\section{Информация об авторе}

Гайнуллин Салим Салимзянович, докторант Болгарской исламской академии, Российская Федерация.

\section{About the author}

Salim S. Gainullin, doctoral student in Bolgar Islamic Academy, the Russian Federation. 
Minbar. Islamic Studies. 2021;14(2)

\section{Раскрытие информации о конфликте интересов}

Автор заявляет об отсутствии конфликта интересов.

\section{Информация о статье}

Поступила в редакцию: 15 ноября 2020 Одобрена рецензентами: 12 мая 2021 Принята к публикации: 02 июня 2021

\section{Conflicts of Interest Disclosure}

The author declares that there is no conflict of interest.

\section{Article info}

Received: November 15, 2020

Reviewed: May 12, 2021

Accepted: June 02, 2021 